\title{
An Examination of the Associations Between Facial Structure, Aggressive Behavior, and Performance in the 2010 World Cup Association Football Players
}

\author{
Keith M. Welker • Stefan M. M. Goetz • \\ Shyneth Galicia • Jordan Liphardt • Justin M. Carré
}

Received: 20 February 2014 / Revised: 4 June 2014 / Accepted: 5 June 2014 / Published online: 11 July 2014 (C) Springer International Publishing 2014

\begin{abstract}
Previous research suggests that facial-width-to-height ratio (FWHR) predicts aggression, unethical behavior, and non-reciprocity of trust. One limitation of this research is that all samples originate from western countries. To overcome this limitation, the present study investigates the relationship between FWHR and performance among association football athletes involved in the 2010 World Cup representing 32 countries. Results indicated that across all 32 countries, the associations between FWHR and athletic performance varied depending on position. FWHR positively predicted fouls within midfielders and forwards, and goals and assists within forwards. Collectively, these findings demonstrate the associations FWHR has with athletic behavior and performance for the first time in a well-varied multinational sample.
\end{abstract}

Keywords Aggression $\cdot$ Facial features $\cdot$ Culture $\cdot$ Competition $\cdot$ Performance $\cdot$ Sports

Recent work suggests that facial-width-to-height ratio (FWHR; Weston et al. 2007) is an important predictor of several psychological constructs and behavior. FWHR, or the ratio of a face's bizygomatic width to the vertical distance between the upper lip to the mid brow, is positively related to antisocial behavior in men, including aggression

We thank Brian Tyminski for assistance with data collection.

Electronic supplementary material The online version of this article (doi:10.1007/s40750-014-0003-3) contains supplementary material, which is available to authorized users.

K. M. Welker $(\bowtie)$

Department of Psychology and Neuroscience, University of Colorado Boulder, Muenzinger D244

345 UCB, Boulder, CO 80309-0345, USA

e-mail: welker.keith@gmail.com

S. M. M. Goetz $\cdot$ S. Galicia $\cdot$ J. Liphardt

Department of Psychology, Wayne State University, 5057 Woodward Avenue, Detroit, MI 48202, USA

J. M. Carré

Nipissing University, North Bay, Canada 
(Carré and McCormick 2008; Goetz et al. 2013), unethical behavior (Haselhuhn and Wong 2011; Geniole et al. 2014), expression of prejudice (Hehman et al. 2013), and the absence of reciprocity (Stirrat and Perrett 2010), especially when individuals are low in social status (Goetz et al. 2013). Not only do wider faced men have these characteristics, but high FWHR men are perceived as being more aggressive (Carré et al. 2009), more dominant (Valentine et al. 2014), and less trustworthy (Stirrat and Perrett 2010) by others. Consistent with the idea that testosterone may in part shape variation in the FWHR (Carré and McCormick 2008), one study also reported that individual differences in testosterone concentrations are positively correlated with FWHR in men (Lefevre et al. 2013). Additionally, other-perceived ratings of masculinity are higher in men with high testosterone (Roney et al. 2006) and FWHR (Geniole and McCormick 2013). Thus, researchers have considered FWHR a biological indicator of dominance and propensity to engage in aggression (Carré and McCormick 2008).

Facial structure has also been linked to prowess in competitive domains. For instance, the FWHR of CEOs was found to be positively related to leadership success and CEOs' organizational performance (Wong et al. 2011). CEOs have also been found to have greater FWHRs than other age and sex-matched controls, and wider faced CEOs being perceived as more dominant and successful (Alrajih, and Ward 2013). The FWHR of US presidents is also positively related to presidents' achievement drive (Lewis et al. 2012). Additionally, high FWHR men are more generous toward ingroup members when in competition with an outgroup (Stirrat and Perrett 2012). Finally, FWHR is positively correlated with baseball performance (home runs) among Japanese men (Tsujimura \& Banissey 2013; but see Mayew 2013 for re-analysis of these data). Thus, although FWHR has been linked to 'undesirable' traits including aggression, unethical behavior, and non-reciprocation of trust, the above studies indicate that FWHR can also predict more desirable traits. Because FWHR can predict performance in success-oriented domains, it is possible that FWHR may not only predict aggressiveness in athletes, but success during competition.

Despite this collection of positive findings, several reports indicate a null relationship between FWHR, aggression, and performance as a main effect or when important covariates such as weight and body mass are included (e.g., Deaner et al. 2012; Efferson and Vogt 2013; Gómez-Valdés et al. 2013; Mayew 2013; Özener 2012 ). Additionally, one limitation of existing research on FWHR, aggression, and dominance is that these findings have been primarily conducted in samples from the United States and Canada with a few notable exceptions that reveal null associations between FWHR and aggressive behavior. Gómez-Valdés et al. (2013) examined the relationship between facial structure and criminal activity in a general population sample of Mexicans and a Mexican prison sample, finding no association between facial structure and whether inmates committed violent crimes. Additionally, other recent work in a sample of Turkish university students finds no association between FWHR and self-reported aggression (Özener 2012). Tsujimura and Banissey (2013) also note a positive association between FWHR and homerun performance in Japanese baseball players, however Mayew (2013) found that controlling for body size nullified this association. Given the mixed findings regarding the associations FWHR has with aggression and performance, and the lack of crossnational studies in this area, further studying the association between FWHR, aggression, athletic performance in a large, multinational sample is valuable to researchers.

The current study overcomes limitations of previous research by examining the association of FWHR with aggression and performance in athletes from the 32 
countries competing in the 2010 World Cup. We hypothesized that FWHR would be positively related to the number fouls committed, assists, and goals scored by association football players. Additionally, it was important to examine several possible covariates and determinants of these effects, including height, weight, and player position. Because the current study operationalized success in performance as goals and assists, it is important to also focus on the associations FWHR had with these outcomes within positions whose purpose is to score these goals.

\section{Methods}

Facial photographs and gameplay data of association football players from the 32 countries competing in the 2010 FIFA world cup finals and qualifying competitions $(N=1,075)$ were obtained from the ESPN website (http://espnfc.com/) between the dates of September 20, 2013 and November 29, 2013. These data contained player statistics from the squads of the 32 nations competing in the 2010 World Cup throughout their international association football careers from 1998 to 2013. These games also included previous world cup tournaments, world cup qualifiers, games and qualifiers from non-World cup tournaments, and exhibition games. The total players included each squad's 23 players competing in the 2010 World Cup Finals and players that competed in the preceding World Cup qualifying tournaments. The thirty-two national teams used in the data analyses are presented in Fig. 1.

Similar to other studies (e.g., Carré and McCormick 2008), goalkeepers $(N=124)$ were removed from the analysis due to having a low, restricted range of total fouls committed $(M=2.23, S D=3.06,45.5 \%$ committed 0 total fouls) compared to other players $(M=146.76, S D=145.29,7.5 \%$ committed 0 total fouls $)$. Of the remaining athletes, 41 others either did not have data from games played, no statistics available, or no available pictures. The remaining data was comprised of 910 athletes.

We obtained photographs of the athletes available from the ESPN website with the athletes looking at the camera. If photographs were not available on the ESPN website or featured athletes not looking directly at the camera and holding a neutral expression,

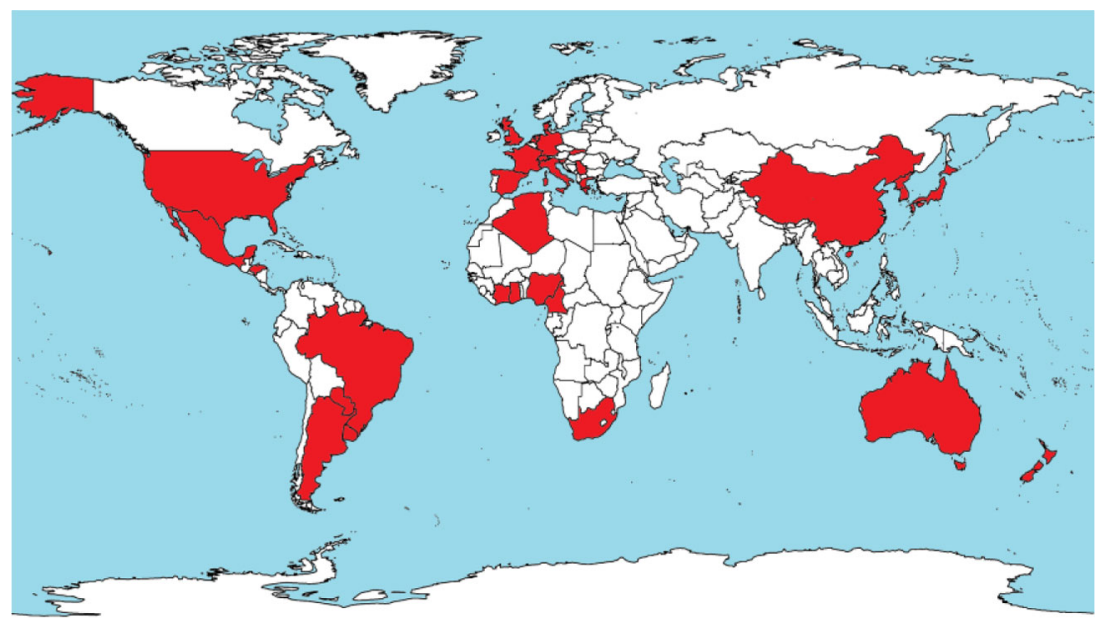

Fig. 1 World map of countries included in the data analyses 
we used internet search engines to find pictures where the athletes were looking as directly at the camera and as close to a neutral emotional expression as possible. With the exception of four cases, researchers found photographs from internet searches that were superior for the measurement of FWHR compared to the ESPN website. Each athlete's FWHR was measured by two out of three trained researchers using ImageJ software, an open-access image measurement software provided by the National Institute of Health (http://rsweb.nih.gov/ij/). Researchers were not aware of the subjects' actual athletic data or each others' measurements when measuring the faces. Measurement consistency was very high for FWHR ( $r \mathrm{~s} \geq .87$, Cronbach's $\alpha \mathrm{s} \geq .93$ ), and measurements were averaged into one index of FWHR for each athlete.

Player Statistics We assessed total fouls committed by players (which do not include offside offenses; FIFA 2013/2014) across all years available, along with yellow cards (broadly speaking, sanctions serving as a warning or temporary suspension, e.g., delaying the restart of play) and red cards (sanctions for more serious offenses, broadly speaking, e.g., violent conduct, serious foul play), and total scored goals. All player statistics were totaled across all available years to form aggregates for each player. Player weight and height were also used as covariates in all analyses, based on reports that athletes' weight (Deaner et al. 2012; Mayew 2013) can attenuate the relationship between FWHR and aggression and that height is associated with fouls, particularly due to referee bias (van Quaquebeke and Giessner 2010). Because the amount of fouls suffered by players may be indicative of experiencing more aggressiveness, rather than engaging in aggressive behavior, fouls suffered was also included as a covariate. Additionally, the total number of games played was used as a covariate and was calculated by summing players' total games started and total times used as a substitute.

Player Position We also used player position (coded $1=$ defender, $2=$ midfielder, $3=$ forward) as an additional covariate. Given that we examined success in performance as a function of goals and assists, it was important to also examine the associations FWHR had with these outcomes within each of the three positions in our data. In association football, defenders are primarily focused on providing support and preventing the opposition from scoring goals. Midfielders often have the duty of maintaining control of the ball and providing the ball to the forwards, who are charged with scoring goals and allowing other players to score goals ("Positions Guide," 2014). Thus, it is important to specifically examine the associations between FWHR with goals and assists within forwards, who are primarily charged with accomplishing these outcomes.

\section{Analytic Strategy}

Our dependent variables were highly skewed with floor effects due to most players not having committed any fouls or scored goals in the data. Additionally, the data used a 2level hierarchical structure, with players nested within teams, except when teams were analyzed individually. Because of this, analyses were conducted using multilevel generalized estimating equations (GEE; Liang and Zeger 1986) with a negative binomial distribution and a robust estimator covariance. The multilevel structure of 
this analysis accounted for the interdependence of the nested structure of the data, which can inflate type I error rates (O'Connell and McCoach 2008), and the negative binomial distribution served to accurately estimate the highly skewed outcome variables (Hilbe 2007).

\section{Results}

Descriptive statistics for the study variables are presented in Table 1. To examine if FWHR predicted fouls committed and goals across all teams, we conducted multilevel generalized estimating equation analyses with a negative binomial distribution, which is a superior method of accounting for the effects because it accounts for skewness and interdependence. Intraclass correlations coefficients (determined from null, intercepts-only multilevel models) for fouls committed $(I C C=.38)$, assists $(I C C=.30)$ and goals scored $(I C C=.09)$ indicated the presence of interdependence, justifying our use of nested models. We also examined the relationship between FWHR, goals assists, and fouls by position. The results of these analyses are presented in Tables 2. Visual assessment of the data through scatterplots revealed two multivariate outliers. Excluding these cases from the analyses did not change the significance of any reported effects.

\section{Fouls Committed}

Across all countries, FWHR only had a marginally significant association with fouls committed $(B=.291,95 \% \mathrm{CI}$ : $[-.040, .622], p=.085)$. When these effects were examined separately for defenders, midfielders, and forwards, the relationship between FWHR and fouls were in a negative, nonsignificant direction in defenders $(B=-.361$, $95 \% \mathrm{CI}$ : $[-.841, .119], p=.140)$, a positive direction for midfielders $(B=.449,95 \% \mathrm{CI}$ : $[.015, .884], p=.043)$, and a more robust positive direction for forwards $(B=.935,95 \%$ CI: $[.401,1.469], p=.001)$.

Yellow and Red Cards Because FWHR was associated with fouls committed in midfielders and forwards, we also examined if FWHR predicted whether players received penalty sanctions. Across all players, FWHR had a nonsignificant, positive trend with total yellow cards $\left(B=.279, \chi^{2}(1)=1.90,95 \% \mathrm{CI}\right.$ : $[-.12, .675], p=.168)$ and red cards received $\left(B=.202, \chi^{2}(1)=.20, p=.659\right)$. We then examined the associations FWHR had with red cards and yellow cards separately by each position. The association between FWHR and yellow cards was in a negative, marginally significant direction in defenders $(B=-.451,95 \%$ CI: $[.-.915, .012], p=.056)$, but was positive in midfielders $(B=.597,95 \% \mathrm{CI}$ : $[.054,1.139], p=.031)$ and forwards $(B=.940,95 \% \mathrm{CI}:[.378,1.502], p=.001)$. For red cards, the pattern of findings were in similar directions, but diminished in magnitude in defenders $(B=-.60,95 \% \mathrm{CI}$ : $[-1.509, .305], p=.193)$, midfielders $(B=.769,95 \% \mathrm{CI}:[-.214,1.751], p=.125)$, and forwards $(B=.532,95 \% \mathrm{CI}:[-.892,1.956], p=.464)$. It is important to note that there was considerable range restriction and decreased variance to be explained in total red cards $(S D=2.20)$, compared to yellow cards $(S D=25.69)$ and compared 


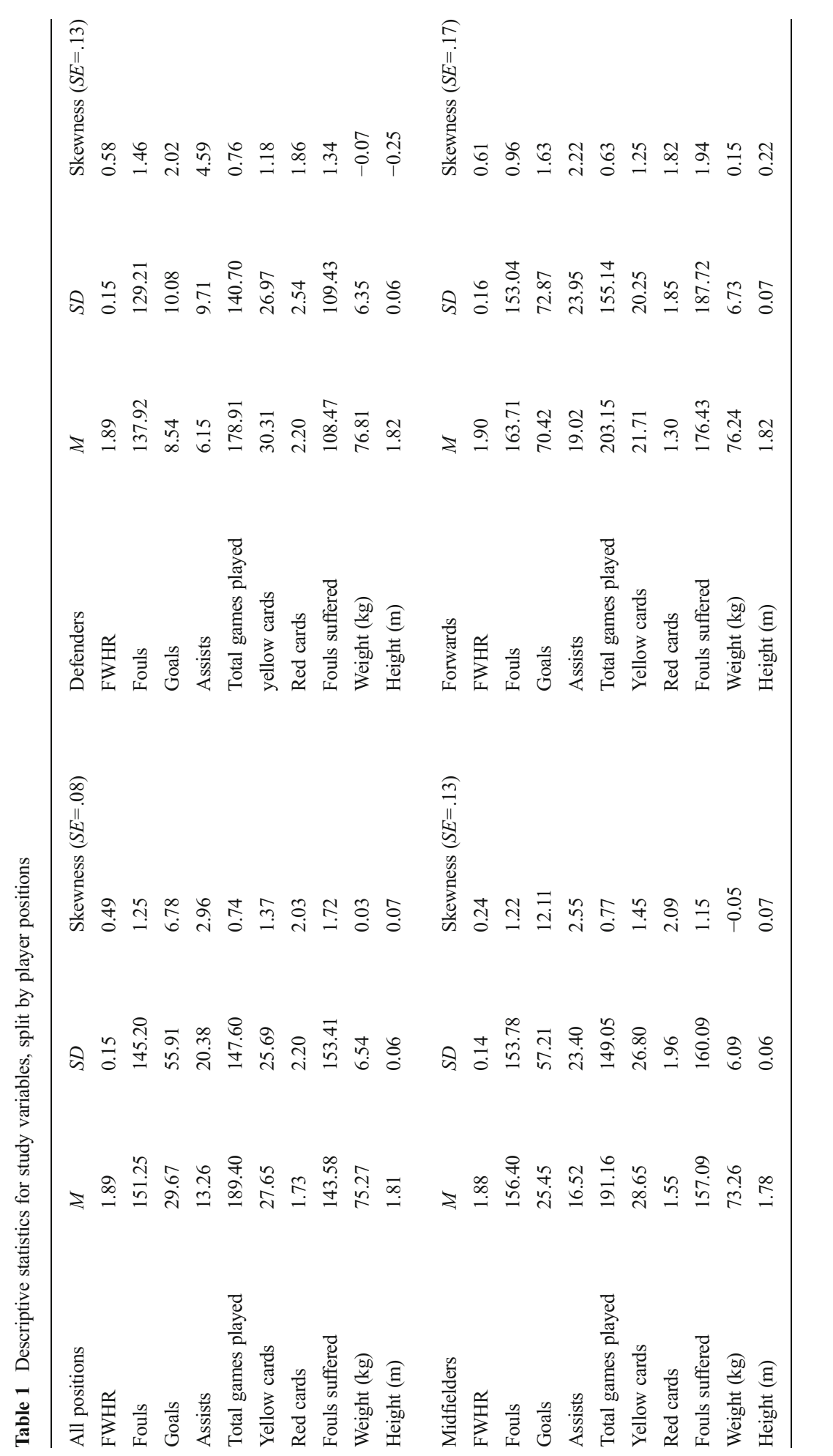




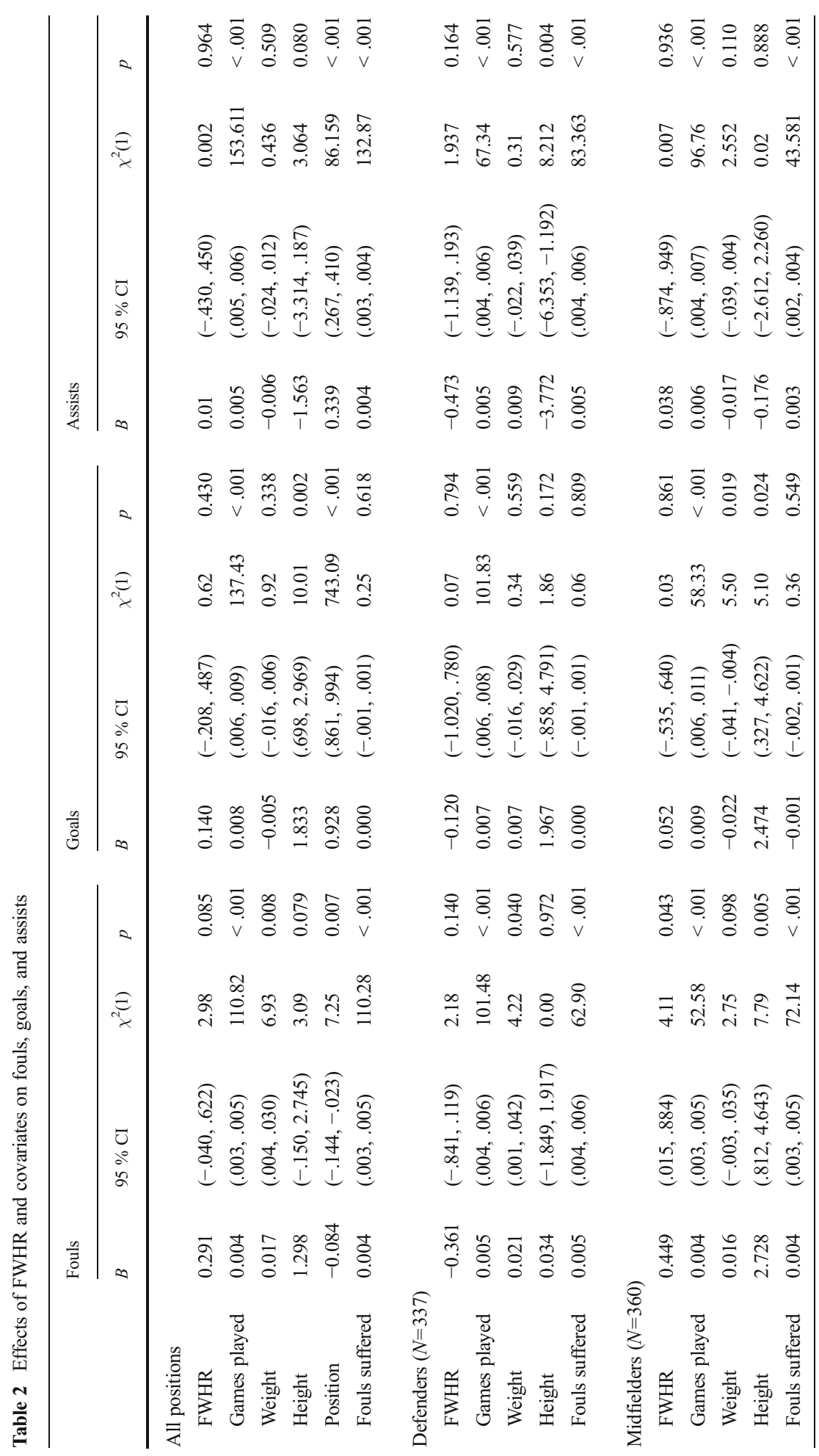




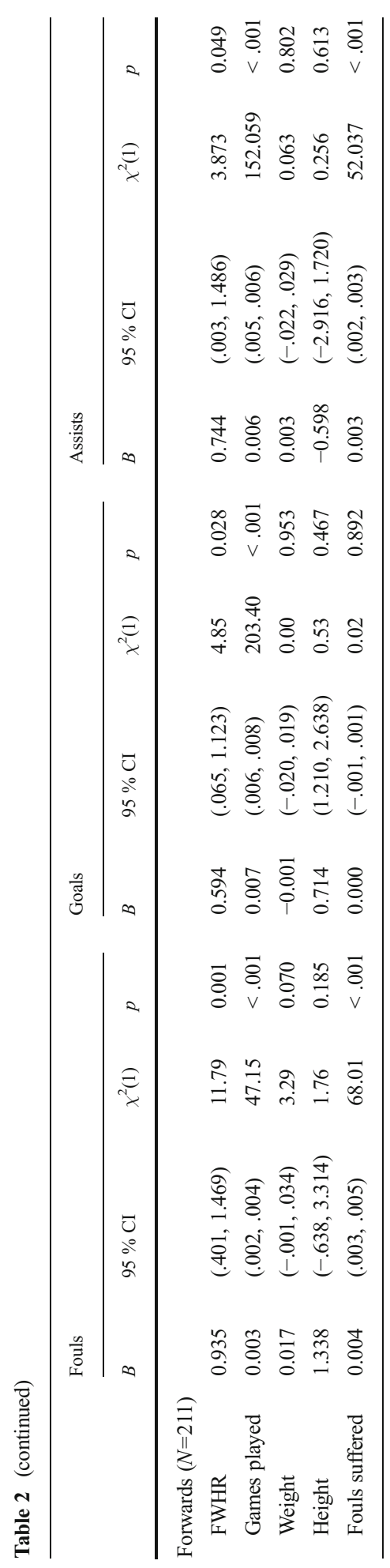


to total fouls committed $(S D=145.22)$, which can reduce statistical power (Cohen 1988).

\section{Goals Scored}

Across all players, FWHR was not associated with goals scored $(B=.140,95 \% \mathrm{CI}$ : $[-.208, .487], p=.430)$. FWHR was not associated with goals in defenders $(B=-.124$, $95 \%$ CI: [ $-1.030, .776], p=.787)$ or midfielders $(B=.039,95 \%$ CI: [-.538, .617], $p=.893$ ). However, in forwards - who have the primary responsibility of scoring goals and creating chances to score goals-FWHR was positively associated with goals scored $(B=.596,95 \%$ CI: [.063, 1.128], $p=.028)$.

\section{Assists}

FWHR was not associated with assists across all players $(B=.010,95 \%$ CI: $[-.430$, $.450], p=.964)$, or within defenders $(B=-.473,95 \%$ CI: $[-1.139, .193], p=.164)$ and midfielders $(B=.038,95 \%$ CI: $[-.874, .949], p=.936)$. However, in forwards, FWHR was positively associated with assists $(B=.744,95 \%$ CI: [.003, 1.486], $p=.049)$.

\section{Additional Analyses}

The previously reported associations FWHR had with assists and goals achieved in forwards indicate that high FWHR forwards are more effective players. However, are high FWHR individuals more likely to be selected to play forward positions? A 1-way ANOVA was conducted to investigate if forwards were more likely to have higher FWHRs compared to other positions. The overall main effect of position was nonsignificant $(F(2,906)=1.27, p=.282)$. Although forwards showed a slightly higher average FWHR $(M=1.899,95 \%$ CI: [1.880, 1.919]), planned comparisons suggested forwards' FWHRs were not significantly higher than defenders $(M=1.886,95 \% \mathrm{CI}$ : [1.870, 1.902], $p=.292)$ or midfielders $(M=1.899,95 \% \mathrm{CI}$ : [1.864, 1.894], $p=.112)$.

Based on previous work modeling the effects of FWHR on athletic behaviors (e.g., Goetz et al. 2013, Study 2), we also examined our analyses with dependent outcomes of fouls, goals, and assists per game. The multilevel negative binomial analyses could not function with noninteger data. Thus, we multiplied players' goals, fouls, and assists per game by 100 and rounded all values to the nearest integer. Because we were dividing fouls by the number of games played, total games played was dropped as a covariate. These analyses indicated a similar pattern of results with diminished significance in FWHR and with the largest, positive effects occurring in forwards (See supplemental materials). However, it is important to note that statistical simulation studies (e.g., Tu et al. 2005; Vickers 2001) have found that fraction-based estimates (e.g., fouls divided by games played) have reduced statistical power compared to using covariates (e.g., controlling for games played). Although these simulation studies were primarily used to make conclusions about ideal assessments of change (using various 
measures of change vs. controlling for baseline values), the statistical implications are the same. Moreover, determining whether a criterion is examined by controlling for a baseline value or dividing by a baseline value is mathematically equivalent to determining whether or not to control for the number of games played in our study or to calculate fouls, goals, and assists per game. Future researchers examining athletic outcomes may also find stronger statistical power in athletic data by examining raw scores controlling for games played, rather than dividing by the number of games played.

We also examined whether height or weight moderated the association between FWHR and fouls committed across all players using moderated multilevel GEE. Neither weight $(B=.013,95 \%$ CI: $[-.030, .056], p=.553)$ nor height $(B=-2.309$, $95 \%$ CI: $[-6.552,1.934], p=.286)$ moderated the association between FWHR and fouls. When the data as split up by player position, these interactions remained nonsignificant $(p s \geq .221)$ with one exception: There was a marginally significant FWHR X weight interaction within forwards $(B=.102,95 \%$ CI: [-.002, .207], $p=.055)$. Decomposing this interaction revealed that forwards' FWHR was associated with fouls when their weight was high $(+1 \mathrm{SD}, B=1.614, S E=.512, p=.002)$, not low $(-1 \mathrm{SD}, B=.241, S E=.466, p=.606)$.

Some researchers have found that body-mass index (BMI) is also an important correlate of FWHR (Coetzee et al. 2010). Based on this research, we also conducted alternate analyses with BMI as a covariate instead of weight. Using BMI as a covariate in place of weight did not alter the significance of any reported findings in this paper.

\section{Discussion}

Across player data from 32 association football teams and six continents, FWHR was positively related to fouls committed and goals scored. The association FWHR had with fouls committed was particularly pronounced in midfielders and forwards. This research suggests that the relationship FWHR has with aggression and player performance can be found in a multinational sample. Additionally, FWHR was predictive of achieved goals and assists within forwards. This finding is particularly important, as existing research on FWHR and behavior has overwhelmingly occurred in western samples.

The relationship FWHR has with goals scored indicates that although high FWHR athletes are more likely to commit fouls, they are also more likely to be successful in competition. This finding suggests that although high FWHR men are more aggressive and likely to cheat, they are also more likely to succeed in competition (e.g., Alrajih, and Ward 2013; Wong et al. 2011; Tsujimura \& Banissey 2013) or possess traits that facilitate success in competition (e.g., Lewis et al. 2012; Stirrat and Perrett 2012). Thus, the increased propensity for high FWHR men to succeed in competitions is an upside to the increased aggressiveness and cheating behaviors found in wider faced men.

An alternative explanation for the present finding is that a player's reputation may influence referee's judgment of whether a foul was committed (Jones et al. 2002). Multiple studies have demonstrated that FWHR is related to personality judgments made by others (e.g., Carré et al. 2009; Haselhuhn, Wong, and Ormiston, 2013; Stirrat and Perrett 2010) thus it is plausible that a referee's judgment could have been influenced by this bias. However, this argument does not apply to the relationship found between FWHR and goals scored since referee judgment is minimally involved. 
While somewhat speculative, the results found for goals scored are consistent with the hypothesis that FWHR is a marker of pubertal testosterone exposure (Carré and McCormick 2008; Verdonck et al. 1999). To the extent that the organizational effects of testosterone exposure affect sensorimotor performance (see e.g. Falter, Arroyo, and Davis, 2006; but see Rahman et al., 2004), which likely enhance a player's skill, one would expect FWHR to map onto player performance. Additionally, a recent study found that FWHR was positively associated with both basal and testosterone reactivity (Lefevre et al. 2013). Thus any direct effects of testosterone on performance may have been captured by FWHR. Future research that directly tests the testosteroneorganizational hypothesis by administering spatial cognition tasks (e.g., mental rotation, targeting, etc.) is needed.

One limitation of the current research is that the number of fouls committed is not a direct indicator of aggressive behavior on the field. Fouls are often given in response to successful and attempted acts of aggression, such as tripping, kicking, strikes, pushes, charging, spitting. However, nonaggressive acts such as holding an opponent or handling of the ball by non-goalkeepers can also result in fouls. Thus, fouls may also be a more direct indicator of unethical and cheating behavior rather than overt aggression in association football. Additionally, fouls are subject to the judgment of a referee and may be given in cases where cheating behavior did not occur, or not given in situations when the referee did not witness actual cheating or aggressive behavior that occurred. Additionally, previous work has identified characteristics that bias the judgments of referees in association football, such as height (van Quaquebeke and Giessner 2010), team reputation (Jones et al. 2002), uniform color (Frank and Gilovich 1988; Tiryaki 2005), previous fouls (Plessner and Betsch 2001), or crowd noise (Nevill et al. 2002). An additional limitation of the current research is that we could not examine the type of game that was played (i.e., "exhibition match vs. world cup qualifying match). It is possible that the type of game played would influence the amount of fouls individuals engage in.

Of additional interest is the magnitude of the associations of FWHR with behavior and personality traits. The current research uses a multilevel structure to reduce the type 1 errors created by interdependence. However, work in multilevel modeling and effect sizes is preliminary and there is no consensus as to which effect sizes are most appropriate (Peugh 2010). This problem is further compounded by the fact that existing multilevel effect sizes are not directly comparable to other parametric effect size estimates commonly used in meta-analyses (Peugh 2010). Given that some researchers have reported moderate to large correlations between FWHR and aggression in men (e.g., $r$ s from to.30 to .54 in Carré and McCormick 2008; Carré et al. 2009) whereas other more recent studies have found smaller effect sizes when including important covariates such as weight (e.g., $r=.09$, Deaner et al. 2012), future researchers may benefit from assuming a small to moderate effect size between FWHR and relevant behaviors exists when taking into account relevant covariates. Recent research also indicates that social status moderates the association between FWHR and aggression, assertiveness, and risk taking in humans and non-human primates (Goetz et al. 2013; Carré 2014; Welker et al. 2014). Thus, the relationship FWHR has with aggression and performance may be dependent on social status, which may help explain the diminished effect sizes and nonsignificant psychological and behavioral correlations with FWHR reported by some researchers. 
In addition to investigating the cultural invariance of the associations between FWHR and behavior, establishing biological mechanisms for these associations is a priority. Because facial structure is related to testosterone in adolescence (Verdonck et al. 1999) and has been argued by some to be a sexually dimorphic predictor of aggressiveness (Weston et al. 2007), future researchers should investigate developmental and hormonal mechanisms that may underlie the relationship between facial structure, success in competitions, and antisocial behavior. FWHR is thought to indicate sexual selection for traits indicating greater success in intermale competition (Weston et al. 2007). Further examinations of behavioral and personality correlates of facial structure in worldwide samples will help further determine whether facial structure is an evolutionarily-derived indicator of fitness and intermale competition success in men.

\section{References}

Alrajih, S., \& Ward, J. (2013). Increased facial width-to-height ratio and perceived dominance in the faces of the UK's leading business leaders. British Journal of Psychology. doi:10.1111/bjop.12035.

Carré, J. M. (2014). Social status, facial structure, and assertiveness in brown capuchin monkeys. Comparative Psychology, 5, 567.

Carré, J. M., \& McCormick, C. M. (2008). In your face: facial metrics predict aggressive behavior in the laboratory and in varsity and professional hockey players. Proceedings of the Royal Society B: Biological Sciences, 275, 2651-2656. doi:10.1098/rspb.2008.0873.

Carré, J. M., McCormick, C. M., \& Mondloch, C. J. (2009). Facial structure is a reliable cue of aggressive behavior. Psychological Science, 20, 1194-1198. doi:10.1111/j.1467-9280.2009.02423.x.

Coetzee, V., Chen, J., Perrett, D. I., \& Stephen, I. D. (2010). Deciphering faces: quantifiable visual cues to weight. Perception, 39(1), 51.

Cohen, J. (1988). Statistical power analysis for the behavioral sciences (2nd ed.). Hillsdale: Erlbaum.

Deaner, R. O., Goetz, S. M. M., Shattuck, K., \& Schnotala, T. (2012). Body weight, not facial width-to-height ratio, predicts aggression in pro hockey players. Journal of Research in Personality, 46, 235-238. doi:10. 1016/j.jrp.2012.01.005.

Efferson, C., \& Vogt, S. (2013). Viewing men's faces does not lead to accurate predictions of trustworthiness. Scientific Reports. doi:10.1038/srep01047. 3.

Falter, C. M., Arroyo, M., \& Davis, G. J. (2006). Testosterone: activation or organization of spatial cognition?. Biological psychology, 73, 132-140.

FIFA. (2013/2014). Law 12: Fouls and misconduct. Retrieved May 30, 2014, from http://www.fifa.com/mm/ document/afdeveloping/refereeing/2.\%201aw\%205_540.pdf

Frank, M. G., \& Gilovich, T. (1988). The dark side of self- and social perception: black uniforms and aggression in professional sports. Journal of Personality and Social Psychology, 54, 74-85.

Geniole, S. N., \& McCormick, C. M. (2013). Taking control of aggression: perceptions of aggression suppress the link between perceptions of facial masculinity and attractiveness. Evolutionary Psychology, 11(5), 1027-1043.

Geniole, S. N., Keyes, A. E., Carré, J. M., \& McCormick, C. M. (2014). Fearless dominance mediates the relationship between the facial width-to-height ratio and willingness to cheat. Personality and Individual Differences, 57, 59-64. doi:10.1016/j.paid.2013.09.023.

Goetz, S. M. M., Shattuck, K. S., Miller, R. M., Campbell, J. A., Lozoya, E., Weisfeld, G. E., \& Carre, J. M. (2013). Social status moderates the relationship between facial structure and aggression. Psychological Science, 24(11), 2329-2334. doi:10.1177/0956797613493294.

Gómez-Valdés, J., Hünemier, T., Quinto-Sánchez, M., Paschetta, C., de Azevedo, S., et al. (2013). Lack of support for the association between facial shape and aggression: a reappraisal based on a worldwide population genetics perspective. PLOS ONE, 8, e52317. doi:10.1371/journal.pone.0052317.

Haselhuhn, M. P., \& Wong, E. M. (2011). Bad to the bone: facial structure predicts unethical behavior. Proceedings of the Royal Society B: Biological Sciences, 279, 1194-1198. doi:10.1098/rspb.2011.1193.

Haselhuhn, M. P., Wong, E. M., \& Ormiston, M. E. (2013). Self-fulfilling prophecies as a link between men's facial width-to-height ratio and behavior. PloS one, 8(8), e72259. 
Hehman, E., Leitner, J. B., Deegan, M. P., \& Gaertner, S. L. (2013). Facial structure is indicative of explicit support for prejudicial beliefs. Psychological Science, 24, 289-296. doi:10.1177/0956797612451467.

Hilbe, J. M. (2007). Negative binomial regression. Cambridge: Cambridge University Press.

Jones, M. V., Paull, G. C., \& Erskine, J. (2002). The impact of a team's aggressive reputation on the decisions of association football referees. Journal of Sports Sciences, 20, 991-1000.

Lefevre, C. E., Lewis, G. J., Perrett, D. I., \& Penke, L. (2013). Telling facial metrics: facial width is associated with testosterone levels in men. Evolution and Human Behavior, 34, 273-279. doi:10.1016/j. evolhumbehav.2013.03.005.

Lewis, G. J., Lefevre, C. E., \& Bates, T. C. (2012). Facial width-to-height ratio predicts achievement drive in US presidents. Personality and Individual Differences, 52, 855-857. doi:10.1016/j.paid.2011.12.030.

Liang, K.-Y., \& Zeger, S. L. (1986). Longitudinal data analysis using generalized linear models. Biometrika, 73, 13-22. doi:10.1093/biomet/73.1.13.

Mayew, W. J. (2013). Reassessing the association between facial structure and baseball performance: a comment on Tsujimura \& Banissy. Biology Letters, 9(5), 20130538. doi:10.1098/rsbl.2013.0538.

Nevill, A. M., Balmer, N. J., \& Williams, M. (2002). The influence of crowd noise and experience upon refereeing decisions in football. Psychology of Sport and Exercise, 3, 261-272.

O'Connell, A. A., \& McCoach, D. B. (2008). Multilevel modeling of educational data. Charlotte: Information Age.

Özener, B. (2012). Facial width-to-height ratio in a Turkish population is not sexually dimorphic and is unrelated to aggressive behavior. Evolution and Human Behavior, 33(3), 169-173.

Peugh, J. L. (2010). A practical guide to multilevel modeling. Journal of School Psychology, 48(1), 85-112.

Plessner, H., \& Betsch, T. (2001). Sequential effects in important referee decisions: the case of penalties in soccer. Journal of Sport and Exercise Psychology, 23, 254-259.

Positions guide: who is in a team? (2014). Retrieved June 2, 2014, from http://news.bbc.co.uk/sport2/hi/ football/rules_and_equipment/4196830.stm.

Rahman, Q., Wilson, G. D., \& Abrahams, S. (2004). Biosocial factors, sexual orientation and neurocognitive functioning. Psychoneuroendocrinology, 29, 867-881.

Roney, J. R., Hanson, K. N., Durante, K. M., \& Maestripieri, D. (2006). Reading men's faces: women's mate attractiveness judgments track men's testosterone and interest in infants. Proceedings of the Royal Society B: Biological Sciences, 273(1598), 2169-2175. doi:10.1098/rspb.2006.3569.

Stirrat, M., \& Perrett, D. I. (2010). Valid facial cues to cooperation and trust: male facial width and trustworthiness. Psychological Science, 21, 349-354. doi:10.1177/0956797610362647.

Stirrat, M., \& Perrett, D. I. (2012). Face structure predicts cooperation: men with wider faces are more generous to their ingroup when out-group competition is salient. Psychological Science, 23, 718-722. doi: $10.1177 / 0956797611435133$.

Tiryaki, M. (2005). Assessing whether black uniforms affect the decisions of Turkish soccer referees: Is the finding of Frank and Gilovich's study valid for Turkish culture? Perceptual and Motor Skills, 100, 51-57.

Tsujimura, H., \& Banissey, M. J. (2013). Human face structure correlates with professional baseball performance: insights from professional Japanese baseball players. Biology Letters, 9(23), 20130140. doi:10. 1098/rsbl.2013.0140.

Tu, Y. K., Blance, A., Clerehugh, V., \& Gilthorpe, M. S. (2005). Statistical power for analyses of changes in randomized controlled trials. Journal of Dental Research, 84(3), 283-287.

Valentine, K. A., Li, N. P., Penke, L., \& Perrett, D. I. (2014). Judging a man by the width of his face: the role of facial ratios and dominance in mate choice at speed-dating events. Psychological Science, 25(3), 806811. doi:10.1177/0956797613511823.

van Quaquebeke, N., \& Giessner, S. R. (2010). How embodied cognitions affect judgments: height-related attribution bias in football foul calls. Journal of Sport \& Exercise Psychology, 32(1), 3-22.

Verdonck, A., Gaethofs, M., Carels, C., \& de Zegher, F. (1999). Effect of low-dose testosterone treatment on craniofacial growth in boys with delayed puberty. European Journal of Orthodontics, 21, 137-143. doi: 10.1093/ejo/21.2.137.

Vickers, A. J. (2001). The use of percentage change from baseline as an outcome in a controlled trial is statistically inefficient: a simulation study. BMC Medical Research Methodology, 1(1), 6.

Welker, KM., Goetz, SMM., \& Carré, JM. (2014). Perceived and experimentally manipulated status moderate the relationship between facial structure and risk taking.

Weston, E. M., Friday, A. E., \& Lio, P. (2007). Biometric evidence that sexual selection has shaped the hominin face. PLoS ONE, 2, 1-8. doi:10.1371/journal.pone.0000710.

Wong, E. M., Ormiston, M. E., \& Haselhuhn, M. P. (2011). A face only an investor could love: CEOs' facial structure predicts their firms' financial performance. Psychological Science, 22, 1478-1483. doi:10.1177/ 0956797611418838 . 